\title{
An international survey on the use of calcium silicate-based sealers in non surgical endodontic treatment
}

\author{
M. Guivarc'h ${ }^{1,2}$, C. Jeanneau ${ }^{3}$, T. Giraud $^{2,3}$, L. Pommel ${ }^{2}$, I. About ${ }^{3}$, A.A. Azim ${ }^{4}$, F. Bukiet ${ }^{2,3}$ \\ ${ }^{1}$ Aix Marseille Univ, EFS/CNRS, ADES, Marseille, France. \\ ${ }^{2}$ Assistance Publique des Hôpitaux de Marseille, France. \\ ${ }^{3}$ Aix Marseille Univ, CNRS, ISM, Inst Movement Sci, Marseille, France. \\ ${ }^{4}$ Department of Periodontics \& Endodontics, School of Dental Medicine, University at Buffalo, Buffalo, \\ New York
}

\section{Corresponding author:}

Prof. Frédéric Bukiet

+33(0)6-43-95-21-83

frederic.bukiet@univ-amu.fr

Head of the Endodontic Department

Faculté d'odontologie de Marseille, 27 Bd Jean-Moulin, 13385 Marseille (France) 


\section{Abstract}

Objectives: To gain insight on the current clinical usage of Bioceramic root canal sealers (BRCS) by general dental practitioners (GDPs) and endodontic practitioners (EPS) and to determine if BRCS clinical application is in accordance with the best available evidence.

Material and methods: An online questionnaire of 18 questions addressing BRCS was proposed to 2335 dentists via a web-based educational forum. Participants were asked about socio-demographic data, clinical practice with BRCS and their motivation for using BRCS. Statistical analysis (Chisquared test or Fisher's exact test) were applied, as appropriate, to assess the association between the variable categories ( $p$-value $<0.05$ ).

Results: The response rate was $28.91 \%$. Among respondents, $94.8 \%$ knew BRCS (EPs more than GDPs, $p<0.05$ ) and $51.70 \%$ were using BRCS. The primary reason for using BRCS was their believe of its improved properties (87.7\%). Among BRCS users, single cone technique (SCT) was the most employed obturation method (63.3\%) which was more applied by GDPs $(p<0.05)$; EPs utilized more of the thermoplasticized obturation techniques $(p<0.05)$. A proportion of $38.4 \%$ of BRCS users indicated the usage of SCT with BRCS regardless of the root canal anatomy (GDPs more than EPs $p<0.05$ ) and $55.6 \%$ considered that BRCS may influence their ability to re-establish apical patency during retreatment (GDPs more than EPs $p<0.05$ ).

Conclusions: This study highlights wide variation in the clinical use of BRCS which is not in accordance with the current literature.

Clinical relevance: This inconsistency among EPs and GDPs on BRCS clinical application requires further clarifications to better standardize their use and improve their future evaluation.

Keywords: Bioceramic root canal sealer, calcium silicate-based sealer, endodontics, root canal filling, single cone technique. 


\section{Introduction}

The primary goal of endodontic treatment is to prevent and to treat apical periodontitis by adequately disinfecting and filling the root canal space [1]. Since reaching a sterile environment is impossible due to the complexity of the root canal system, filling and sealing of the latter is essential to prevent the passage of residual microorganisms and their by-products into the peri-radicular tissues [2]. Several obturation techniques combining gutta-percha and a root canal sealer have been used to seal the root canal space including the "single cone technique" (SCT) [3]. This technique relies primarily on one gutta-percha cone and more emphasis is placed on the sealer which functions as a root canal filler. Among the available root filling techniques, SCT is considered to be less technique-sensitive as well as cost-effective [4]. However, a higher sealer volume inside the root canal space may negatively influence the seal as most available sealers tend to shrink upon setting [5]. As a result, SCT combined with conventional sealers was deemed inappropriate, and up till now it was recommended to maximize the gutta percha volume and minimize the sealer thickness [6] using thermoplasticized gutta-percha obturation techniques. Since Mineral Trioxide Aggregate development, silicate-based materials are widely used in endodontic procedures because of their excellent biological properties [7]. This explains the advent of calcium silicate-based sealers also known as bioceramic root canal sealers (BRCS) [8] characterized by handling and viscosity properties optimized for obturation of the root canal space. Recently, SCT has been updated with BRCS usage considering that the latter do not shrink upon setting [9]. On the other hand, thermoplasticized gutta-percha obturation techniques are controversial with this type of sealers [10,11].

Given the increasing BRCS release into the market, an international survey was set up to examine the knowledge and clinical application of these materials by endodontic practitioners (EPs) and general dental practitioners (GDPs) in order to determine if the latter were in accordance with the best available evidence. 


\section{Material and methods}

A descriptive, cross-sectional and international survey was conducted online in November 2017 with two recalls set 15 days apart. A multiple-choice self-administered questionnaire was sent by e-mail to all members identified as dentists on a web-based educational forum, "Endolit". At the time of the investigation, it represented 2335 practitioners of whom $62.4 \%$ were registered on this forum as endodontic specialists, $11.1 \%$ as endodontic residents and $26.5 \%$ as GDPs. This close-ended questionnaire included 18 questions related to BRCS endodontic use (Fig. 1). All participants were asked to provide socio-demographic data on their age, gender, practice experience, type of practice and geographic region. Other questions focused on dentists' knowledge about BRCS, the way they apply the material during endodontic treatment, as well as their motivation and perception toward BRCS. All participants received a written explanation of the terms of the study prior to their participation and had to give their informed consent to participate in the study without any financial compensation. This survey was approved by the Ethics Committee of Aix-Marseille University, France (reference 2018-06-02-002).

\section{Statistical analysis}

Statistical analysis was performed using SPSS Statistics (IBM, Armonk, USA). The participants of the present study were categorized into two groups; General dental practitioners (GDPs) or Endodontic practitioners (EPs). The EPs group included both endodontic specialists and endodontic residents considering that their undergoing specialty training, education and clinical practice are monitored by endodontic specialists. First, the distribution by age ( 5 classes), gender, years of practice (4 classes) and type of practice (GDPs/EPs) was examined with regard to the following two points: "has heard of BRCS before" and "has already used BRCS". The rest of the analysis was conducted only with the respondents who reported using BRCS at a frequency ranging from "sometimes" to "always" (Fig. 1). In this part, we were particularly interested in the influence of the type of practice (GDPs VS EPS) on clinical habits with BRCS usage, and the perception about the material. Chi-squared test $\left(\mathrm{X}^{2}\right)$ or Fisher's exact test were used, as appropriate, to assess the associations between the variable categories ( $p$-value<0.05). 


\section{Results}

\section{Characteristics of dentists included in the study}

Of the 2335 contacted dentists, 675 practitioners gave their informed consent yielding a response rate of $28.9 \%$. Participants were from: North America (50.8\%), Europe (22.8\%), Asia/Australia (16.3\%), South America (5.9\%) and Africa (4.2\%). The age of the participants ranged from 23 to 85 years [mean \pm standard deviation (SD): $43.9 \pm 13$; median $=41$ ] and years of practice ranged from 0 to 62 years [mean \pm SD: $18.1 \pm 12.9$; median=15]; $80.3 \%$ of them were EPs and $19.7 \%$ GDPs (Table 1 ).

\section{Knowledge and usage of BRCS}

Among the participants $(n=675), 94.8 \%$ had heard about BRCS before $(n=640)$, which was significantly associated with being in the EPs group $(p<0.05)$ (Table 2). Participants knew about BRCS via: "conferences/course" (57.50\%), followed by "manufacturers' speech/advertising" $(22.2 \%)$, "colleagues' experience" (12.2\%), "literature" (4.1\%) and "websites/internet" (1.5\%).

Among the respondents knowing BRCS, 58.4\% had used BRCS at least once ( $n=374)$, which was significantly associated with being in the EPs group $(p<0.05)$ (Table 2). These latter were further asked how often they used BRCS in their daily practice (Fig. 1). The distribution of the frequency of BRCS usage was: "always" (22.2\%), "frequently" (22.4\%), "sometimes" (48.7\%) and "never" $(6.7 \%)$ and couldn't be related to the type of practice $(p>0.05)$ (Table 2). For the subsequent statistical analysis, those describing a BRCS usage ranging from "sometimes" to "always" were identified as "BRCS users" ( $n=349)$ and had to answer questions related to their clinical practice with BRCS and reasons for using them. This subgroup represented $51.7 \%$ of the overall participants and was composed of $87.4 \%$ EPs and $12.6 \%$ GDPs.

\section{BRCS clinical practice}

\section{Canal drying}

Among BRCS users, $69.4 \%$ employed paper points alone to dry canals prior to obturation, $19.6 \%$ used vacuum and paper points, $10.1 \%$ used alcohol before paper points and $0.9 \%$ used vacuum alone.

\section{BRCS application}

For BRCS application, $51 \%$ of BRCS users employed a device helping injection and distribution of the sealer into the root canal (either a Lentulo spiral $8 \%$, a specific injection tip $40.7 \%$, a file $2 \%$ or a sonic/ultrasonic system $0.3 \%$ ). The remaining $49 \%$ carried out a simple coating of the master cone with BRCS.

\section{Obturation technique with BRCS}

Among BRCS users, $63.3 \%$ employed SCT for root canal obturation; $16.7 \%$ used cold lateral compaction and $46.1 \%$ used thermoplasticized gutta-percha obturation technique (either carrier-based obturation or warm vertical compaction). Systematic use of SCT with BRCS was reported by $40.7 \%$ of BRCS users. There was a significant association between the obturation method and the type of practice: GDPs tended to use SCT more $(p<0.05)$ while EPs used warm obturation techniques more often $(p<0.05)$ (Fig. 2). BRCS users were also asked about the obturation methods they used with 
other sealers than BRCS. Our results highlighted that the preferential obturation method significantly changed depending on the type of sealer used, independently of the type of practice. SCT was the most implemented technique with BRCS $(p<0.05)$ while warm vertical compaction was preferentially used with other types of sealers $(p<0.05)$ (Fig. 3). Specific bioceramic nanoparticles preimpregnated/pre-coated gutta-percha cones were used by only $22.1 \%$ of the BRCS users. There was no significant association between using these specific cones and the type of practice $(p>0.05)$.

\section{Motivations and perception toward BRCS}

The improved biological and physicochemical properties appeared as the main reason for using BRCS, followed by the possibility to fill simultaneously the root canal space and a perforation. These two motivations were not associated with the type of practice. On the other hand, reasons such as the innovative aspect of BRCS, the simplification of clinical procedures, the connection with minimal invasive dentistry (preservation of coronal, pericervical and radicular dental tissue) and the fact that no specific equipment for obturation would be needed all showed significant association with being a GDP $(p<0.05)$ (Table 3).

To the question "Do you think BRCS usage with SCT can be indicated regardless of the root canal anatomy?", 38.4\% of the BRCS users answered "Yes", 57.6\% answered "No" and 4\% had no opinion. Thinking that BRCS usage with SCT could be indicated regardless of the root canal anatomy was significantly associated with being in the GDPs group (68.2\%) rather than in the EPs group (34.1\%) $(p<0.05)$.

To the question "Do you think BRCS usage may influence the ability to re-establish apical patency during non-surgical retreatment?", 55.6\% of the BRCS users answered "Yes" and it was significantly associated with being in the GDPs group (68.2\%) rather than in the EPs group $(51.8 \%)(p<0.05)$. 


\section{Discussion}

The present study aimed to gain insight into the current use of BRCS, to discuss the clinical practices reported by endodontic practitioners (EPs) and general dental practitioners (GDPs) and to determine if it was in accordance with the best available evidence.

To our knowledge, this is the first international survey addressing BRCS use in root canal obturation. Previously conducted surveys on endodontic practices often included one category of practitioners (either GDPs or EPs) and only within a single country [12-14]. The present survey considered and compared both type of practice and utilized the data-base of a web-based endodontic forum that is available to clinicians world-wide. Despite Endolit being based in the United States, the practitioners registered on this website are from different countries and more than a half of the respondents were not practicing in the United States (55.7\%). The number of contacted dentists was consistent $(n=2335)$ and the global response rate achieved (close to $30 \%$ ) as well as the gender ratio were in line with previously conducted surveys on the dentists' knowledge and type of clinical practice [13,14]. The distribution between EPs and GDPs among respondents $(80.3 \%$ and $19.7 \%$ respectively) was coherent with its distribution in the overall population included in the survey $(73.5 \%$ of EPs, $26.5 \%$ of GDPs).

The results of this survey highlighted a widespread knowledge of BRCS among the respondents (94.8\%). Despite the presence of numerous alternative root canal sealers, BRCS was quite popular since $51.7 \%$ of the participants used these materials in their clinical practice. Being an EP appeared to be a determining factor in using BRCS $(p<0.05)$. The primary reason for using this type of sealers was their improved biological and physicochemical properties (87.7\% of BRCS users), regardless of the type of practice. This finding clearly indicates that most practitioners are aware of BRCS properties. Indeed it has been shown that BRCS properties are overall similar or better than those of conventional root canal sealers $[9,15]$. Indeed, several studies compared physico-chemical and biological properties of different BRCS formulations such as iRoot SP (Innovative Bioceramix, Vancouver, Canada) / EndoSequence BC (Brasseler, Savannah, GA, USA), BioRoot ${ }^{\mathrm{TM}}$ RCS (Septodont, Saint-Maur-desFossés, France) or Endoseal MTA (Maruchi, Wonju, Korea) versus widely used root canal sealers such as Pulp Canal Sealer (SybronEndo, Orange, CA, USA) a zinc oxide eugenol-based sealer, or $\mathrm{AH}$ Plus (Dentsply DeTrey GmbH, Konstanz, Germany) an epoxy resin-based sealer [9,15].

BRCS generally fulfil general endodontic sealer requirements (ISO 6876) regarding radioopacity, film thickness, solubility and flow $[9,15,16]$. The specific biological properties of BRCS are due to the presence of calcium silicates whose setting reaction leads to hydration byproducts such as hydroxyl and calcium ions and calcium hydroxide followed by a precipitation reaction with calcium phosphate leading to hydroxyapatite formation. This results in dentinal interaction forming a mineral infiltration zone [17] with higher tubule penetration and push-out strength properties for iRoot SP [15]. BRCS generally provide a good antimicrobial activity [15] without cell toxicity [18,19] and are also reported to be biocompatible inducing periodontal ligament stem cell proliferation and migration [20]. Moreover, previous studies have demonstrated BRCS bioactivity on periodontal cells. Indeed their interaction with periodontal ligament cells demonstrated an increased secretion of angiogenic growth factors (VEGF and FGF-2) and the osteogenic factors (BMP-2) [18]. In addition, in vitro stimulation 
murine osteoblast precursor cell line by BRCS led to an increased DMP-1 expression and mineral biological properties may help the periodontal healing process in case of apical periodontitis.

The attraction toward a "new" product and simplification of the root canal filling procedure appeared as strong arguments in favor of BRCS usage for GDPs $(p<0.05)$. However, our findings showed that the clinical practices still remain controversial. For instance, it is well known that drying the canals is a prerequisite before applying conventional endodontic sealers since moisture can affect their setting and adhesion properties [21]. On the contrary, hydration of BRCS is needed to trigger the setting process and to take advantage of their enhanced properties previously mentioned. Surprisingly, our investigation showed that around $10 \%$ of BRCS users used alcohol in combination with a paper point to dry the canals, which is known to lead to dentin dehydration $[22,23]$. The degree to which such procedures can impact the bond strength of BRCS deserves further investigation especially since different adverse effects have been shown between some root canal irrigants and BRCS [24,25]. In a similar manner, changes in BRCS physical properties has been shown to occur when subjected to high temperatures associated with warm vertical obturation techniques [10,11]. Despite this fact, almost half of the respondents $(46.1 \%)$ including more EPs $(p<0.05)$ implemented-thermoplasticized gutta-percha obturation techniques. These findings suggest that many practitioners, a fortiori EPs, may tend to rely on their clinical convenience when using BCRS rather than considering the available evidence or respecting the manufacturers' recommendations. It should be noted that a new BRCS has been recently introduced that is intended to be used with warm gutta-percha techniques (BC HiFlow, Brassler, Savannah, GA, USA) [26]. This survey, however, was conducted prior to the release of this product to the dental market.

In a recently published clinical study, the use of SCT with BRCS has shown a high success rate (around 90\%) for both initial treatment and retreatment [27]. However, no long-term clinical studies about BRCS usage are available yet. The presence of voids has been observed regardless of the root canal filling technique and may result in the proliferation of residual microorganisms and jeopardize the long-term outcome [28]. Although SCT may be suitable for filling tapered-rounded canals, it can result in more voids in irregularly shaped anatomies compared to other filling techniques, regardless of the type of the sealer [29-32]. In the present study, $63.3 \%$ of BRCS users implemented SCT for root canal obturation in some of their cases and around $40 \%$ used it on every case. Among BRCS users, $38.4 \%$ thought that SCT combined with BRCS can be indicated on every case regardless of the root canal configuration, especially among GDPs $(p<0.05)$. EPs, however, tended to adapt the obturation method to the type of sealer. SCT was significantly associated with BRCS usage while warm vertical compaction was the most used obturation technique with sealers other than BRCS $(p<0.05)$. Among the participants, $51 \%$ declared employing devices such as an injection tip or a Lentulo spiral for sealer insertion into the root canal. Such practices have been shown to reduce voids in the root canal filling [33] and may be recommended.

Sealability of SCT with BRCS partially depends on the interface between the gutta-percha (hydrophobic) and the sealer (hydrophilic). Some manufacturers claim improvement of this interface 
thanks to the use of nanoparticles bioceramic pre-impregnated gutta-percha cones. However, a recent BRCS than pre-impregnated ones [34]. Thus, the fact that only $22 \%$ of BRCS users implemented these specific pre-coated gutta cones may not affect the obturation quality.

Finally, one of the controversies linked to BRCS usage is their retreatability since the material may become impenetrable given its hardness upon setting [35]. Most studies have shown that apical patency can be properly re-established if the master cone fitted to the full working length [35-39]. However, the adequacy between the retreatment method and the clinical relevance can be questioned since most non-surgical retreatments are indicated in case of obturation short of the radiographic apex and associated with apical periodontitis [40]. While patency has been reported to be achieved when chloroform is used [41], other studies reported that it was often impossible to gain apical patency on curved canals when fillings are short of the working length [35]. This suggests that BRCS presence beyond the master cone may make endodontic retreatment challenging. The fact that $44.4 \%$ of BRCS users considered that these sealers may not influence their ability to re-establish apical patency during retreatment (especially among EPs $p<0.05$ ) suggests either that BRCS retreatability may not be considered as a major clinical issue or that practitioners are underestimating this problem. It should also be taken into account that non surgical endodontic retreatment does not only aim to re-establish apical patency but also achieving complete removal of the previous root canal filling materials as well as cleaning and disinfection of the root canal space [42].

Some limitations should be noted regarding the present survey. Indeed, it utilized a web-based forum primarily dedicated to endodontics. Thus, it can be hypothesized that the GDPs population surveyed may have a particular interest in this specialty. Therefore, our findings should not be generalized to all dentists. As with any survey, another limitation of the study is the self-declaration of the respondents concerning their type of practice. Indeed, the specific requirements to become EPs are location sensitive as well as the recognition of endodontics as an official dental specialty.

\section{Conclusions}

This study highlights wide variation in the clinical practices which are not often in accordance with the current literature on BRCS. The participants of this international survey tend to rely on their clinical habits rather than following the manufacturers' recommendations or considering the best available evidence when using BCRS. This inconsistency implies to provide further clarifications on BRCS clinical application which may pave the way to better standardize their use and improve their future evaluation.

\section{Acknowledgment}

The authors of this manuscript deny any conflict of interest.

\section{Compliance with ethical standards}

Conflict of interest: Dr Maud Guivarc'h declares that she has no conflict of interest. Dr Charlotte 
Jeanneau declares that she has no conflict of interest. Dr Thomas Giraud declares that he has no conflict of interest. Dr Ludovic Pommel declares that he has no conflict of interest. Prof Imad About declares that he has no conflict of interest. Dr Adham A Azim declares that he has no conflict of interest. Prof Frédéric Bukiet declares that he has no conflict of interest.

Funding: No funding was received.

Ethical approval: This survey was approved by the Ethics Committee of Aix-Marseille University, France (reference 2018-06-02-002).

Informed consent: Informed consent was obtained from all individual participants included in the study. 


\section{References}

1 Hülsmann M, Peters OA, Dummer PMH (2005) Mechanical preparation of root canals: shaping goals, techniques and means. Endod Top 10:30-76.

2 Vertucci FJ (2005) Root canal morphology and its relationship to endodontic procedures. Endod Top 10:3-29.

3 Tomson RME, Polycarpou N, Tomson PL (2014) Contemporary obturation of the root canal system. Br Dent J 216:315-22.

4 Wu M-K, van der Sluis LWM, Wesselink PR (2006) A 1-year follow-up study on leakage of single-cone fillings with RoekoRSA sealer. Oral Surg Oral Med Oral Pathol Oral Radiol Endod 101:662-7.

5 Ørstavik D, Nordahl I, Tibballs JE (2001) Dimensional change following setting of root canal sealer materials. Dent Mater Off Publ Acad Dent Mater 17:512-9.

6 De-Deus G, Coutinho-Filho T, Reis C, Murad C, Paciornik S (2006) Polymicrobial leakage of four root canal sealers at two different thicknesses. J Endod 32:998-1001.

7 Kaur M, Singh H, Dhillon JS, Batra M, Saini M (2017) MTA versus Biodentine: Review of Literature with a Comparative Analysis. J Clin Diagn Res JCDR 11:ZG01-ZG05.

8 Camilleri J (2017) Will Bioceramics be the Future Root Canal Filling Materials? Curr Oral Health Rep 4:228-38.

9 Silva Almeida LH, Moraes RR, Morgental RD, Pappen FG (2017)Are Premixed Calcium Silicate-based Endodontic Sealers Comparable to Conventional Materials? A Systematic Review of In Vitro Studies. J Endod 43:527-35.

10 Camilleri J (2015) Sealers and warm gutta-percha obturation techniques. J Endod 41:72-8.

11 DeLong C, He J, Woodmansey KF (2015) The effect of obturation technique on the push-out bond strength of calcium silicate sealers. J Endod 41:385-8.

12 Bjørndal L, Reit C (2005) The adoption of new endodontic technology amongst Danish general dental practitioners. Int Endod J 38:52-8.

13 Savani GM, Sabbah W, Sedgley CM, Whitten B (2014) Current Trends in Endodontic Treatment by General Dental Practitioners: Report of a United States National Survey. J Endod 40:618-24.

14 Setzer FC, Hinckley N, Kohli MR, Karabucak B (2017) A Survey of Cone-beam Computed Tomographic Use among Endodontic Practitioners in the United States. J Endod 43:699-704.

15 Donnermeyer D, Bürklein S, Dammaschke T, Schäfer E (2018) Endodontic sealers based on calcium silicates: a systematic review. Odontology doi:10.1007/s10266-018-0400-3.

16 Jafari F, Jafari S (2017) Composition and physicochemical properties of calcium silicate based sealers: A review article. J Clin Exp Dent 9:e1249-55.

17 Atmeh AR, Chong EZ, Richard G, Festy F, Watson TF (2012) Dentin-cement interfacial interaction: calcium silicates and polyalkenoates. J Dent Res 91:454-9.

18 Camps J, Jeanneau C, El Ayachi I, Laurent P, About I (2015) Bioactivity of a Calcium Silicate-based Endodontic Cement (BioRoot RCS): Interactions with Human Periodontal Ligament Cells In Vitro. J Endod 41:1469-73.

19 Giacomino CM, Wealleans JA, Kuhn N, Diogenes A (2019) Comparative Biocompatibility and Osteogenic Potential of Two Bioceramic Sealers. J Endod 45:51-6.

20 Collado-González M, García-Bernal D, Oñate-Sánchez RE, Ortolani-Seltenerich PS, Lozano A, Forner L, et al. (2017) Biocompatibility of three new calcium silicate-based endodontic sealers on human periodontal ligament stem cells. Int Endod J 50:875-84.

21 Zmener O, Pameijer CH, Serrano SA, Vidueira M, Macchi RL (2008) Significance of moist root canal dentin with the use of methacrylate-based endodontic sealers: an in vitro coronal dye leakage study. J Endod 34:76-9.

22 Nagas E, Uyanik MO, Eymirli A, Cehreli ZC, Vallittu PK, Lassila LVJ, et al. (2012) Dentin moisture conditions affect the adhesion of root canal sealers. J Endod 38:240-4.

23 Taşdemir T, Er K, Çelik D, Tahan E, Serper A, Ceyhanli KT, et al. (2014) Bond strength of calcium silicate-based sealers to dentine dried with different techniques. Med Princ Pract Int J Kuwait Univ Health Sci Cent 23:373-6.

24 Razmi H, Bolhari B, Karamzadeh Dashti N, Fazlyab M (2016) The Effect of Canal Dryness on Bond Strength of Bioceramic and Epoxy-resin Sealers after Irrigation with Sodium Hypochlorite or Chlorhexidine. Iran Endod J 11:129-33.

25 Arias-Moliz MT, Camilleri J (2016) The effect of the final irrigant on the antimicrobial activity of root canal sealers. J Dent 52:30-6.

26 Buchanan S (2018) Warm gutta-percha obturation with BC HiFlow ${ }^{\mathrm{TM}}$ Sealer. Endod Pract US.

27 Chybowski EA, Glickman GN, Patel Y, Fleury A, Solomon E, He J (2018) Clinical Outcome of NonSurgical Root Canal Treatment Using a Single-cone Technique with Endosequence Bioceramic Sealer: A Retrospective Analysis. J Endod 44:941-5. 
28 Hammad M, Qualtrough A, Silikas N (2009) Evaluation of root canal obturation: a three-dimensional in vitro study. J Endod 35:541-4.

29 Celikten B, Uzuntas CF, Orhan AI, Orhan K, Tufenkci P, Kursun S, et al. (2016) Evaluation of root canal sealer filling quality using a single-cone technique in oval shaped canals: An In vitro Micro-CT study.

Scanning 38:133-40.

30 Gordon MPJ, Love RM, Chandler NP (2005) An evaluation of .06 tapered gutta-percha cones for filling of .06 taper prepared curved root canals. Int Endod J 38:87-96.

31 Celikten B, F Uzuntas C, I Orhan A, Tufenkci P, Misirli M, O Demiralp K, et al. (2015) Micro-CT assessment of the sealing ability of three root canal filling techniques. J Oral Sci 57:361-6.

32 Viapiana R, Moinzadeh AT, Camilleri L, Wesselink PR, Tanomaru Filho M, Camilleri J (2016) Porosity and sealing ability of root fillings with gutta-percha and BioRoot RCS or AH Plus sealers. Evaluation by three ex vivo methods. Int Endod J 49:774-82.

33 Guinesi AS, Faria G, Tanomaru-Filho M, Bonetti-Filho I (2014) Influence of sealer placement technique on the quality of root canal filling by lateral compaction or single cone. Braz Dent J 25:117-22.

34 Eltair M, Pitchika V, Hickel R, Kühnisch J, Diegritz C (2018) Evaluation of the interface between guttapercha and two types of sealers using scanning electron microscopy (SEM). Clin Oral Investig 22:1631-9.

35 Hess D, Solomon E, Spears R, He J (2011) Retreatability of a bioceramic root canal sealing material. J Endod 37:1547-9.

36 Ersev H, Yilmaz B, Dinçol ME, Dağlaroğlu R (2012) The efficacy of ProTaper Universal rotary retreatment instrumentation to remove single gutta-percha cones cemented with several endodontic sealers. Int Endod J 45:756-62.

37 Neelakantan P, Grotra D, Sharma S (2013) Retreatability of 2 mineral trioxide aggregate-based root canal sealers: a cone-beam computed tomography analysis. J Endod 39:893-6.

38 Carpenter MT, Sidow SJ, Lindsey KW, Chuang A, McPherson JC (2014) Regaining apical patency after obturation with gutta-percha and a sealer containing mineral trioxide aggregate. J Endod 40:588-90.

39 Donnermeyer D, Bunne C, Schäfer E, Dammaschke T (2018) Retreatability of three calcium silicatecontaining sealers and one epoxy resin-based root canal sealer with four different root canal instruments. Clin Oral Investig 22:811-7.

40 Di Filippo G, Sidhu SK, Chong BS (2014) Apical periodontitis and the technical quality of root canal treatment in an adult sub-population in London. Br Dent J 216:E22.

41 Oltra E, Cox TC, LaCourse MR, Johnson JD, Paranjpe A (2017) Retreatability of two endodontic sealers, EndoSequence BC Sealer and AH Plus: a micro-computed tomographic comparison. Restor Dent Endod 42:19-26.

42 Rossi-Fedele G, Ahmed HM (2017) Assessment of Root Canal Filling Removal Effectiveness Using Micro-computed Tomography: A Systematic Review. J Endod 43:520-6. 


\section{Figures Legends}

Figure 1: Survey questionnaire

Figure 2: Obturation techniques implemented by BRCS users with BRCS according to the type of practice $(\%)(n=349)$

CLC, Cold Lateral Compaction; GDPs, General dental practitioners; EPs, Endodontic practitioners; SCT, Single Cone Technique; WV, Warm Vertical. $\left({ }^{*}\right)$ represents significant differences between two groups $(p<0.05)$.

Figure 3: Obturation techniques implemented by BRCS users according to the type of sealer (\%) $(\mathrm{n}=\mathbf{3 4 9})$

CLC, Cold Lateral Compaction; SCT, Single Cone Technique; WV, Warm Vertical. $\left(^{*}\right)$ represents significant differences between two groups $(p<0.05)$. 
Table 1 Distribution of participants $(n=675)$

\begin{tabular}{rr}
\multicolumn{1}{l}{ Continent } & $\%$ \\
& \\
Africa & 4.2 \\
Asia/Australia & 16.3 \\
Europe & 22.8 \\
North America & 50.8 \\
South America & 5.9
\end{tabular}

Age (years)

$\begin{array}{rr}<30 & 12.2 \\ 30-39 & 31.0 \\ 40-49 & 24.4 \\ 50-59 & 15.7 \\ \geq 60 & 16.7\end{array}$

Gender

$\begin{array}{rr}\text { Male } & 72.3 \\ \text { Female } & 27.7\end{array}$

Years of Practice

$\begin{array}{rr}0-10 & 34.5 \\ 11-20 & 29.3 \\ 21-30 & 16.9 \\ \geq 30 & 19.3\end{array}$

Type of practice

$\begin{array}{rr}\text { GDPs } & 19.7 \\ \text { EPS } & 80.3\end{array}$


Table 2 Knowledge and usage of BRCS

\begin{tabular}{ccccc}
\hline & $\begin{array}{c}\text { GDPs } \\
(\%)\end{array}$ & $\begin{array}{c}\text { Eps } \\
(\%)\end{array}$ & $\begin{array}{c}\text { Global } \\
(\%)\end{array}$ & $\begin{array}{c}P \\
\text { Value }\end{array}$ \\
\hline Has already heard of BRCS $(\mathrm{n}=675)$ & 83.5 & 97.6 & 94.8 & $\mathrm{p}<0.05$ \\
Has already used BRCS $(\mathrm{n}=640)$ & 41.0 & 62.0 & 58.4 & $\mathrm{p}<0.05$ \\
$\qquad$ From "sometimes" to "always" (n=374) & 95.7 & 93.0 & 93.3 & $\mathrm{p}>0.05$ \\
$\quad$ (BRCS users) & & & & \\
\hline
\end{tabular}


Table 3 Reasons for using BRCS ( $n=349$ )

\begin{tabular}{lcccc}
\hline & $\begin{array}{c}\text { GDPs } \\
(\%)\end{array}$ & $\begin{array}{c}\text { EPs } \\
(\%)\end{array}$ & $\begin{array}{c}\text { Global } \\
(\%)\end{array}$ & $P$ Value \\
\hline $\begin{array}{l}\text { Biological and physicochemical } \\
\text { properties }\end{array}$ & 88.6 & 87.5 & 87.7 & $\mathrm{p}>0.05$ \\
$\begin{array}{l}\text { Possibility to fill simultaneously the root } \\
\text { canal and a perforation }\end{array}$ & 38.6 & 36.4 & 36.7 & $\mathrm{p}>0.05$ \\
$\begin{array}{l}\text { Attraction toward a new biomaterial } \\
\text { Simplification and saving time }\end{array}$ & 47.7 & 30.2 & 32.4 & $\mathrm{p}<0.05$ \\
$\begin{array}{l}\text { Connection with minimal invasive } \\
\text { dentistry }\end{array}$ & 47.7 & 23.9 & 26.9 & $\mathrm{p}<0.05$ \\
No specific equipment for obturation & 29.5 & 14.4 & 16.3 & $\mathrm{p}<0.05$ \\
\hline
\end{tabular}




\section{Questionnaire}

Dear colleagues,

We would like to attract your attention on an online study regarding your practice in root canal filling. We would be very grateful if you could give us some of your time by spending a few minutes filling out a questionnaire. Filling the questionnaire does not require any specific knowledge and only refers to your own clinical experience. The time required is about 5 minutes and the data collected is strictly anonymous. There is absolutely no obligation to participate in this study and your decision to contribute will be considered as informed consent. Aware that your time is valuable, we are very grateful for the attention you will give to the completion of this survey.

Thank you for your time and assistance.

1. I have received information about the conditions of this study and I give my informed consent to contribute.

$\square$ Yes $\quad \square$ No (end of the questionnaire)

2. Have you ever heard about Bioceramic root canal sealers (BRCS)?

$\square$ Yes $\quad \square$ No (go to question 13)

\section{How have you first known about BRCS?}

$\square$ Through conferences / courses $\quad \square$ Through manufacturers / advertising

$\square$ Through another dentist's experience $\quad \square$ Other

4. Have you ever used BRCS?

$\square$ Yes $\quad \square$ No (go to question 13)

5. At what frequency do you estimate the use of BRCS in your daily practice?

Never (go to question 13) $\quad \square$ Sometimes

Frequently $\square$ Always (i.e. in every case)

6. When using BRCS, how do you generally dry the root canal?

Sterile paper points alone $\square$ With alcohol before using sterile paper points

With sterile paper points combined with Luer vacuum adapter (or equivalent system)

Other (specify)

7. When using BRCS, how do you generally apply the sealer?

Simple gutta cone coating $\quad \square$ Injection tip

Lentulo spiral $\square$ Other (specify)

8. When using BRCS, which obturation technique do you use? (multiple answers possible)

Warm vertical compaction $\square \quad \square$ Cold lateral compaction $\square$ Carrier-based obturation

Single cone technique $\quad \square$ Other (specify)

9. What type of gutta percha cones do you currently use with BRCS?

Bioceramic nanoparticles pre-coated gutta percha cones $\square$ Non pre-coated cones

10. What was your motivation to use BRCS in your practice? (multiple answers possible)

Biological and physico-chemical properties of this type of sealers

Significant saving time and simplification

No need of special equipment devoted to root canal obturation

Possibility to fill simultaneously the root canal and a root perforation

$\checkmark$ Connection with minimal invasive endodontics (preservation of coronal, pericervical and radicular dental tissue) 
Willingness to try this recent biomaterial

11. It is generally recommended to use BRCS with single cone technique. Do you think this method can be indicated regardless of the root canal anatomy?

$\square$ Yes $\quad \square$ No

12. Do you think BRCS usage may influence the ability to re-establish apical patency during non-surgical retreatment?

$\square$ Yes $\quad \square$ No

13. If you do not use BRCS, which obturation technique do you use? (multiple answers possible)

Warm vertical compaction

$\square$ Cold lateral compaction

Carrier-based obturation

Single cone technique

Other (specify)

14. What is your gender?

Male $\quad \square$ Female

15. How old are you? (years)

16. In which year did you graduate as a dentist?

17. Do you practice as...

A general practitioner $\quad \square$ An endodontist practitioner

A postgraduate student/resident in endodontics

18. Where do you practice?

Africa

Asia/Australia

Europe

North America

South America 
Figure 2

100

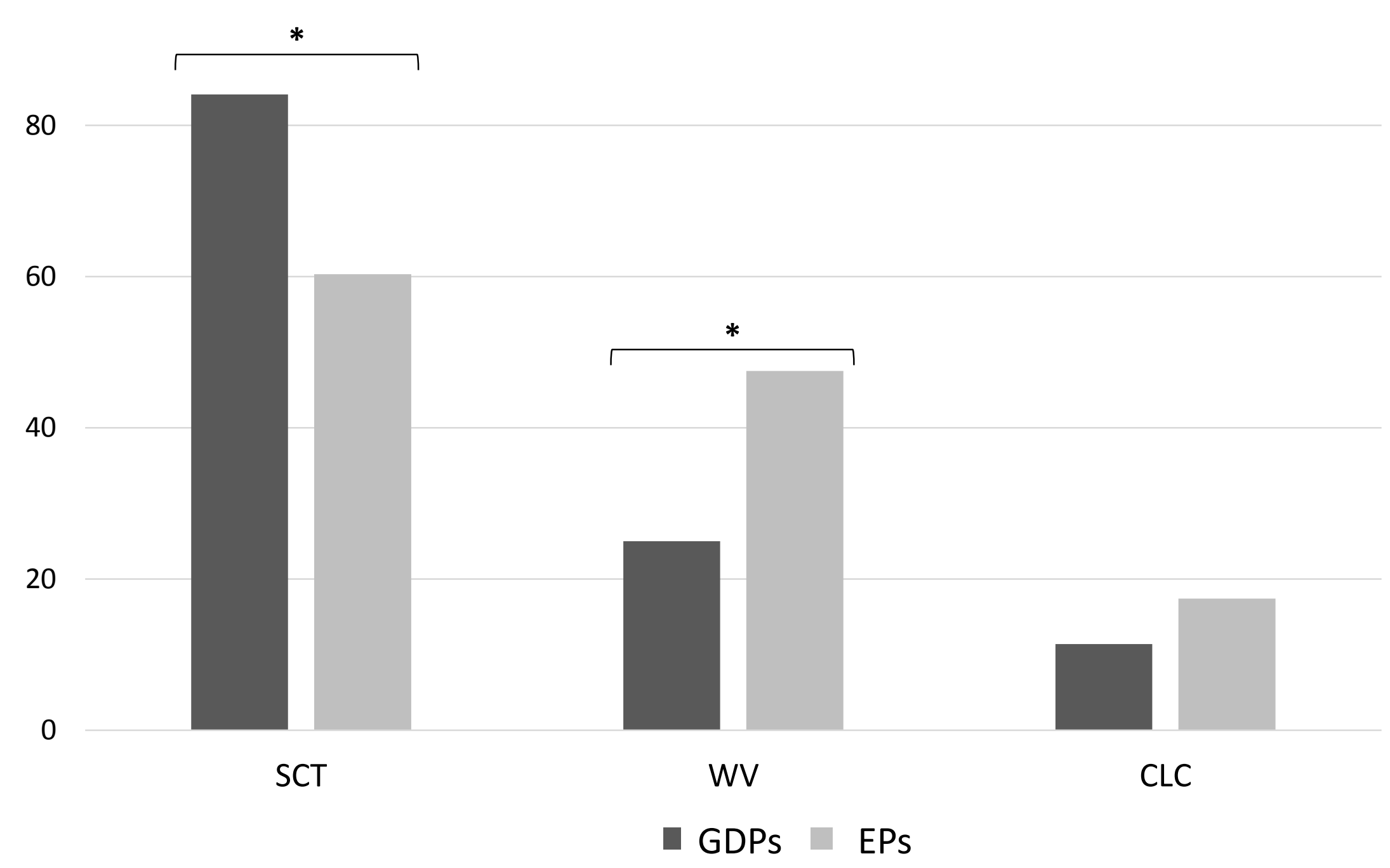


80

*

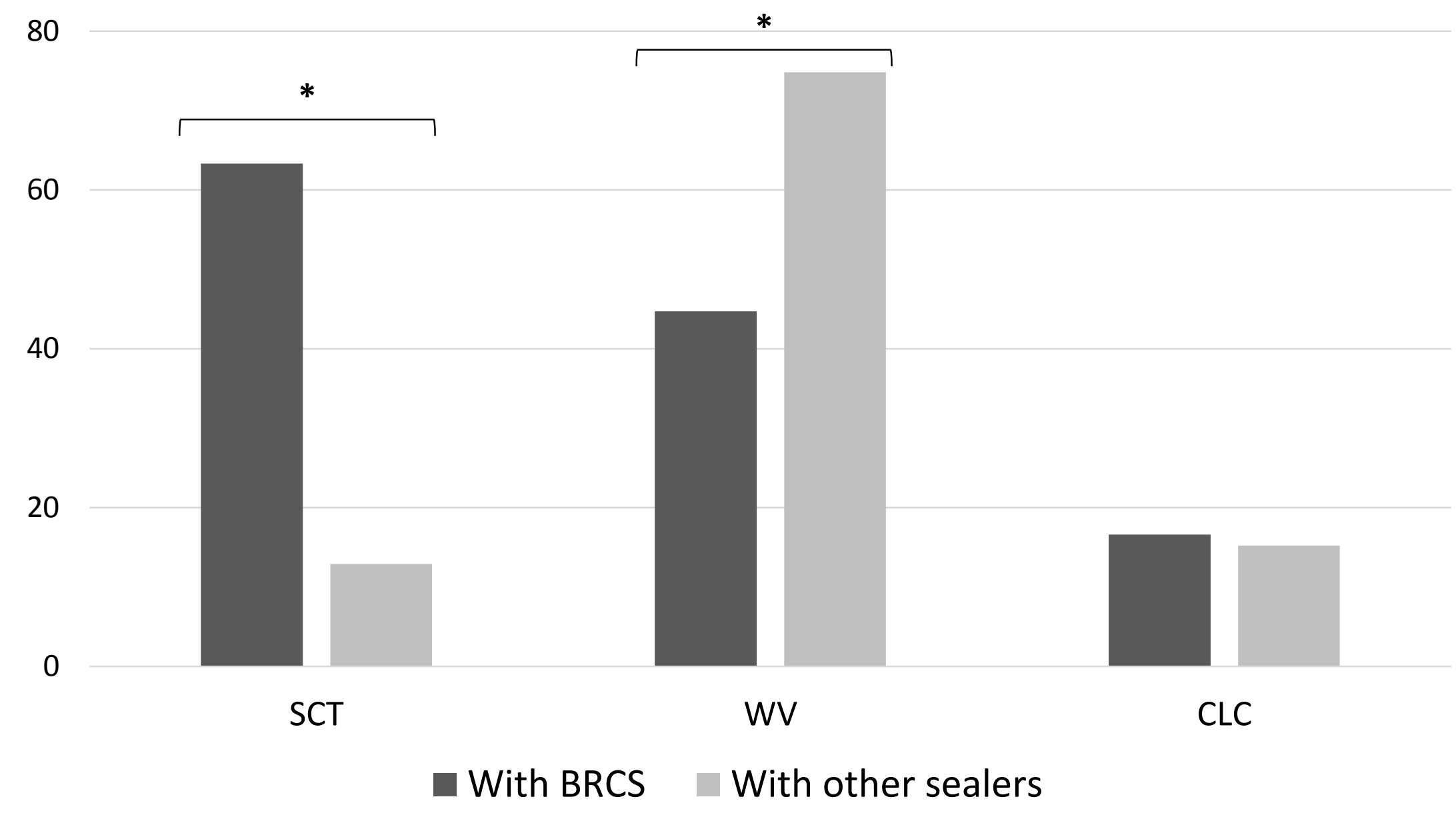

Figure 